\title{
The first pterosaur trackways from Japan
}

\author{
Yuong-Nam Lee ${ }^{a, *}$, Yoichi Azuma ${ }^{b}$, Hang-Jae Lee ${ }^{a}$, Masateru Shibata ${ }^{b}$, Junchang Lü ${ }^{c}$ \\ ${ }^{a}$ Korea Institute of Geoscience and Mineral Resources, Daejeon 305-350, Republic of Korea \\ ${ }^{\mathrm{b}}$ Fukui Prefectural Dinosaur Museum, Katsuyama 911-8601, Japan \\ ${ }^{\mathrm{c}}$ Institute of Geology, Chinese Academy of Geological Sciences, Beijing 100037, China
}

\section{A R T I C L E I N F O}

\section{Article history:}

Received 9 June 2009

Accepted in revised form 7 November 2009

Available online $\mathrm{xxx}$

\section{Keywords:}

Pterosaur tracks

Pteraichnus nipponensis

Lower Cretaceous

Kitadani Formation

Japan

\begin{abstract}
A B S T R A C T
In 1990, five well-preserved pterosaur trackways were discovered in the Kitadani Formation (Lower Cretaceous) of the Kitadani Dinosaur Quarry, Fukui Prefecture, Japan. They occur on the surface of an isolated dark grey siltstone slab $(70 \times 50 \mathrm{~cm})$ along with amphibian and bird tracks as well as feeding marks. All pterosaur trackways (a total of 64 imprints) show a clear quadrupedal gait pattern comprising manus and pes prints which reflect their detailed anatomy of the feet. Manus and pes imprint is very small, average $22.6 \mathrm{~mm}$ and $21.9 \mathrm{~mm}$ long, respectively. The manus has an anteriorly oriented digit I imprint with a medially oriented hook-like sharp claw mark, which makes a high divarication (average $155.4^{\circ}$ ) between the posteriorly oriented digit III imprint. The high digital abduction clearly shows that digit I of the manus could be more hyper-extended anteriorly than previously thought: spreading the digits as much as possible would provide a more stable contact with substrate as well as better support the center of pterosaur body mass displaced anteriorly. The interdigital webbing of the pes imprint extends from the metatarso-phalangeal joint near to the bases of four claws. As these features clearly distinguish the Kitadani pterosaur trackways from five known ichnospecies of Pteraichnus, we assign them to a new ichnospecies, Pteraichnus nipponensis. Abundant small pterosaur ichnotaxa from Spain, Korea, and Japan indicate that many small pterodactyloid pterosaur species existed in the Early Cretaceous although there is no single skeletal datum yet.
\end{abstract}

(c) 2009 Elsevier Ltd. All rights reserved.

\section{Introduction}

Since the first pterosaur trackway (Pteraichnus saltwashensis) was described from the Morrison Formation in 1957 (Stokes, 1957), the ichnologic record of Late Jurassic to Late Cretaceous pterosaurs has increased significantly in recent years (Lockley et al., 1995, 2001; Mazin et al., 1995, 1997; Wright et al., 1997; Garcia-Ramos et al., 2000; Calvo and Lockley, 2001; Fuentes Vidarte, 2001; Meijide Calvo, 2001; Meijide Fuentes, 2001; Hwang et al., 2002; Rodriguez-de la Rosa, 2003; Kim et al., 2006; Li et al., 2006; Zhang et al., 2006; Lee et al., 2008). Except for two pterosaur ichnotaxa from Oncala, Soria, Spain (Fuentes Vidarte et al., 2004a,b), Asia has produced the most abundant pterosaur tracks of the world. Five pterosaur tracksites have been discovered so far in Asia, all from Cretaceous rock units. The first evidence of pterosaur tracks from Asia came from the Uhangri Formation (Upper Cretaceous) in Korea (Lockley et al., 1997) and was later named Haenamichnus uhangriensis (Hwang et al., 2002). The two other Korean occurrences are

\footnotetext{
* Corresponding author.

E-mail address: ylee@kigam.re.kr (Y.-N. Lee).
}

Pteraichnus isp. from the Haman Formation (Lower Cretaceous) (Kim et al., 2006), and Pteraichnus koreanensis from the Hasandong Formation (Lower Cretaceous) (Lee et al., 2008). The fourth tracksite is in the Hekou Formation (Lower Cretaceous) in China, from which was found cf. Pteraichnus (Li et al., 2006; Zhang et al., 2006). The fifth report is a single manus-pes print set from the Tetori Group of Toyama Prefecture in Japan, which is not described in detail yet (Fujita, 2008).

In 1990, new pterosaur trackways were discovered in the uppermost part of the Kitadani Formation (Lower Cretaceous) of the Tetori Group at the Kitadani Dinosaur Quarry, Katsuyama City, Fukui Prefecture in Japan (Fig. 1). It represents the first pterosaur trackways in Japan and the sixth occurrence in Asia. The new pterosaur trackways are an important contribution to the growing database of pterosaurian ichnites in Asia as well as an important datum for Cretaceous pterosaur track sites. Japan of this time was a part of eastern Asia, juxtaposed to the Korean peninsula from the Late Jurassic to the middle Miocene (Otofuji et al., 1985; Lee et al., 1996). The new tracks are of particular interest because they are very similar to Pteraichnus koreanensis in Korea by size, but different from it morphologically. In addition, the Kitadani pterosaur tracks show clear trackway patterns while not in Pteraichnus

0195-6671/\$ - see front matter (c) 2009 Elsevier Ltd. All rights reserved. doi:10.1016/j.cretres.2009.11.001 

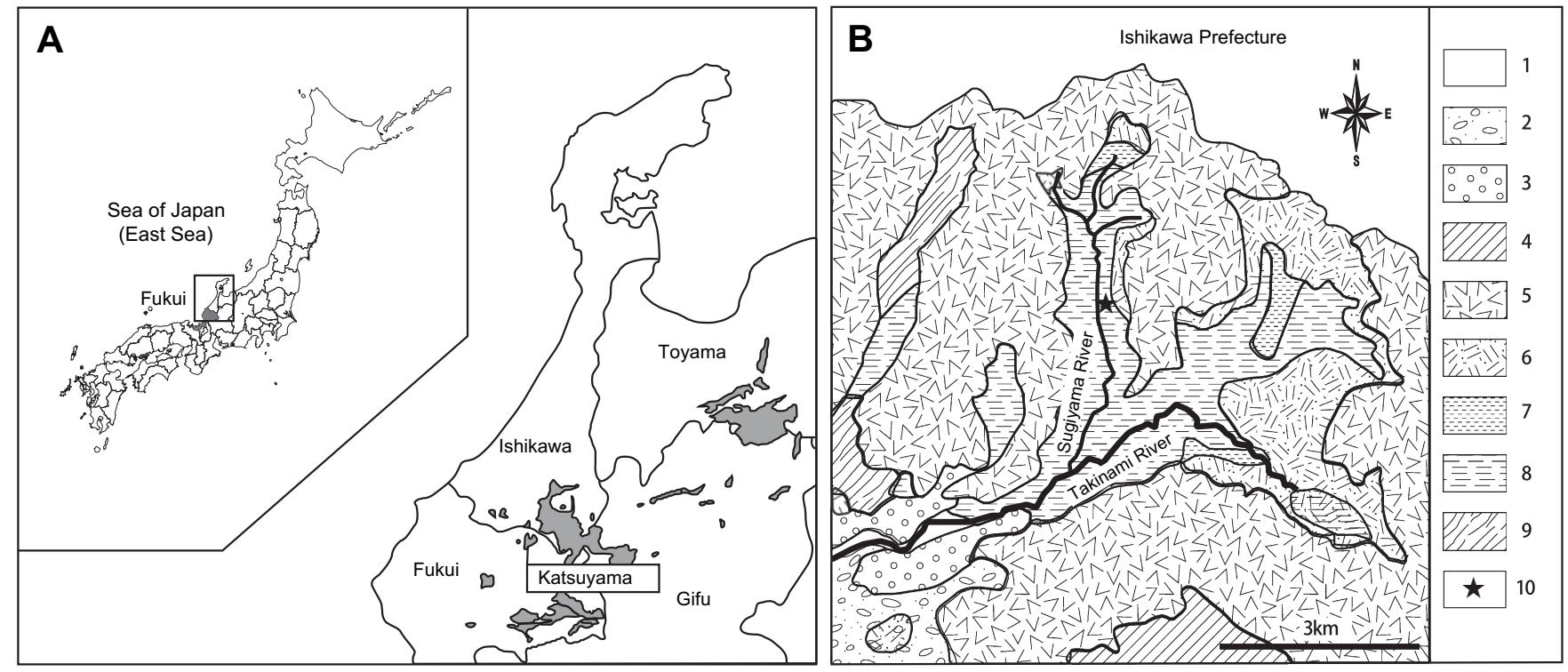

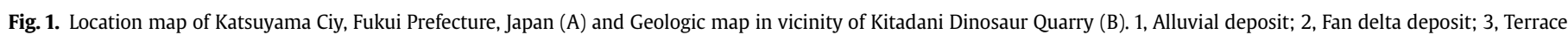
deposit; 4, Glassy andesitic rock; 5, Andesitic rock; 6, Nohi rhyolite; 7, Omichidani Formation; 8, Tetori Group; 9, Hida metamorphic rock; 10, Kitadani Dinosaur Quarry.

koreanensis (Lee et al., 2008). The purpose of this paper is to describe the new pterosaur tracks from the Kitadani Formation, Katsuyama City in Japan and to compare them with other small pterosaur tracks, especially Pteraichnus koreanensis and two pterosaur ichnotaxa from Oncala, Soria, Spain.

\section{Geological setting}

The trackways described here are from the Kitadani Formation of the Kitadani Dinosaur Quarry, which is on the Sugiyama River within the city limits of Katsuyama in Fukui Prefecture. The Kitadani Formation forms the uppermost part of the Akaiwa Subgroup, the uppermost subgroup within the Tetori Group. The Tetori Group is subdivided into three subgroups, the Kuzuryu, Itoshiro, and Akaiwa subgroups in ascending order. The Tetori Group has produced the most diverse vertebrate faunas and ichnofaunas from the Mesozoic sediments of Japan (Fujita, 2003). In the Takinami River region, the Akaiwa Subgroup consists of the upper Akaiwa Formation and Kitadani Formation, which the latter is exposed in and around the quarry (Fig. 1). Especially, the quarry is one of the most important sites for the Cretaceous vertebrate fossils in Japan. Through a series of excavations starting in 1988, the quarry has produced many important vertebrate fossils which include abundant amiiform fish scales, five taxa of eucryptodire turtles (Hirayama, 2002), a goniopholidid crocodyliform (Kobayashi, 1998), and dinosaurs such as Fukuiraptor kitadaniensis (Azuma and Currie, 2000; Currie and Azuma, 2006), Fukuisaurus tetoriensis (Kobayashi and Azuma, 2003), a new dromaeosaurid and a new titanosauriform sauropod (Shibata and Azuma, 2008; Shibata and Goto, 2008) as well as various dinosaur and bird footprints (Azuma, 2003).

The quarry consists of about $2,500 \mathrm{~m}^{2}$ of exposure, representing the middle upper part of the Kitadani Formation. The well exposed vertical section in the quarry is characterized by the alternation of coarse to fine grey to white sandstone and dark grey to black siltstone associated with greenish tuffaceous rock (Fig. 2). They indicate that at least two meandering river channel fills and three fining-upward sequences (Fujita, personal communication). No distinct marine or offshore deposits have been identified in the quarry. The quarry has four footprint horizons with two bonebeds (Azuma, 2003; Shibata and Goto, 2008). The pterosaur tracks were discovered on an isolated block from a dark grey siltstone layer at the second footprint horizon during the excavation in 1990 (Fig. 3). This layer also contains various ichnofossils such as amphibian, bird, theropod and ornithopod dinosaur tracks as well as various invertebrate traces. The combined record from body fossils (fishes, turtles, crocodyliforms, theropod, sauropod, and ornithopod dinosaurs), and ichnofossils clearly indicate that diverse vertebrate communities existed during the time of Kitadani deposition.

The Kitadani Formation yields some nonmarine molluscan fossils reliable for the geological age. These faunas include Trigoniodes (Wakinoa) tetoriensis, Plicatounio naktongensis, Nagdongia soni, Pseudohyria matusmotoi, Nippononaia tetoriensis, and Nippononaia ryosekiana (Tamura, 1990; Isaji, 1993). They have been found in late Hauterivian to early Aptian sediments in Japan and South Korea (Maeda, 1962; Tashiro and Okuhira, 1993; Isaji, 1993). The age of the terrestrial unit of the Sebayashi Formation of the Monobegawa Group in the Outer Zone of Southwestern Japan is well controlled chronologically by ammonite bearing units above and below. Especially, Nippononaia ryosekiana from the Kitadani Formation is known as a key species of the upper Barremian Sebayashi type fauna (Kozai et al., 2002). In addition, the zircon fission track ages obtained from tuff samples of the Wasabu Alternation and the Bessandani Formation which correlated with the horizons above and below the Kitadani Formation is $113 \pm 6 \mathrm{Ma}$ and $127 \pm 8 \mathrm{Ma}$, respectively (Gifu-ken Dinosaur Research Committee, 1993; Board of Education of Toyama Prefecture, 2002). Therefore, the age of Kitadani Formation could be assigned to late Barremian on the basis of occurrences of N. ryosekiana and radiometric data (Fujita, 2003). Charophyte gyrogonites from the Kitadani Formation also agree with the Barremian age (Kubota, 2005).

\section{Systematic description}

Order: Pterosauria Kaup, 1834

Superfamily: Pterodactyloidea Plieninger, 1901

Ichnogenus Pteraichnus Stokes, 1957

Ichnospecies Pteraichnus nipponensis ichnosp. nov.

Holotype. Five pterosaur trackways on a siltstone slab $(70 \times 50 \mathrm{~cm})($ FPDM-F022-1: Fukui Prefectural Dinosaur Museum, Footprint Collection, Katsuyama, Fukui). 

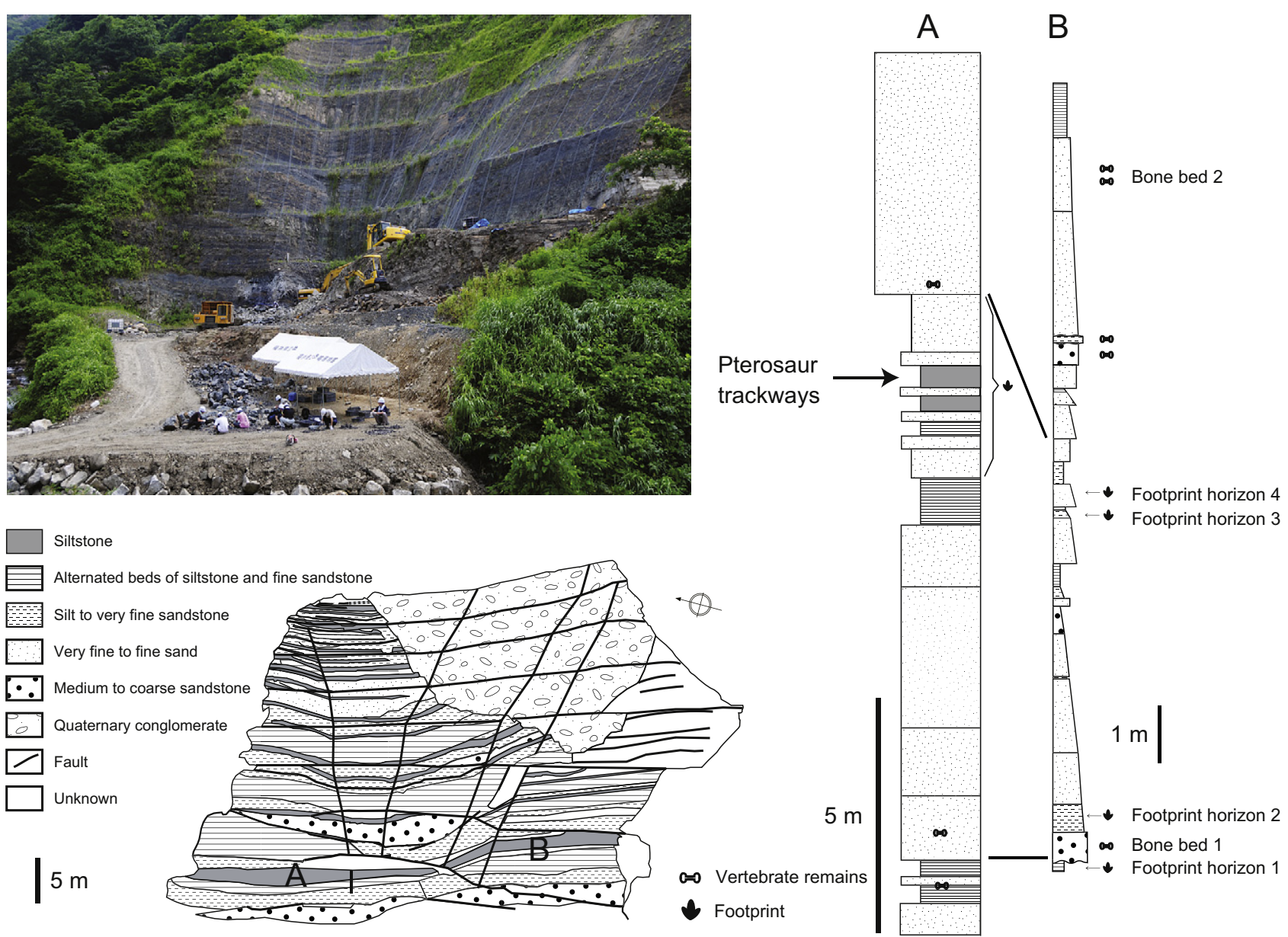

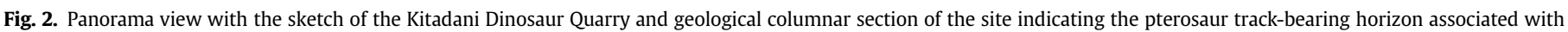
other fossils.

Type locality and horizon. Kitadani Formation, Lower Cretaceous, Kitadani Dinosaur Quarry, Katsuyama City, Fukui Prefecture, Japan.

\section{Etymology. Named after Japan which yielded the holotype.}

Diagnosis. Quadruped track; manus print more laterally to the pes print; pes print anterior to the manus print; the asymmetrical manus track with three digit imprints; anteriorly oriented digit I imprint with a medially oriented hook-like sharp claw mark; anteriorly curved tip of digit II imprint; posteriorly oriented and nearly straight or slightly medially curved digit III; digit III over 1.5 times longer than digit I and II which are nearly same in length; divarication of digit I and III impressions is very high (average $155.4^{\circ}$ ); the metacarpo-phalangeal joint depression is shallower than the digital impressions; triangular, elongate and fully plantigrade and tetradactyl pes print; laterally curved four claw marks; interdigital webbing extended from the metatarso-phalangeal joint near to the bases of the claws; the divarication of digit I and II impressions smaller than that between II and III, III and IV; the digit I imprint is the shortest and other three digit imprints roughly subequal in length; the metatarso-phalangeal joint part usually wider and deeper than the heel of the pes.

Description. The slab contains 84 pterosaur tracks with amphibian and bird tracks as well as feeding marks. The feeding marks appear as different sized round depressions $(n=17>6.3 \mathrm{~mm}$ in diameter, Fig. 3). They could be beak marks of pterosaurs and/or birds, judging from the occurrence of their trackways on the slab.
We focus on only pterosaur tracks herein and other trace fossils will be dealt with a separate topic later. The pterosaur tracks visible on the slab clearly show quadrupedal locomotion without tail trails, although some prints are overprinted or missing. The tracks are preserved as positive depressions which are not underprints (Fig. 3).

Although tracks are shallowly depressed and very small in size, the quality of impression of the autopod anatomy is good in some imprints enough to make detailed description (Fig. 4). Except for isolated tracks, the average manus and pes length is $22.6 \mathrm{~mm}$ and $21.8 \mathrm{~mm}$ in five trackways, respectively. The manus prints are asymmetrical, with three digit imprints. In general, the digit I imprint is anteriorly oriented and slightly curved distally with a clear hook-like sharp claw mark. The claw mark is oriented medially. Digit II is oriented laterally and appears straight rod-like. The claw mark is not as clear as the digit I but slightly curved anteriorly on the tip. Digit III is oriented posteriorly and nearly straight or slightly curved medially and ends with a sharp mark that represents a claw. Digit III is over 1.5 times longer than digit I and II which are nearly same in length. Divarication of digit I and III impressions ranges from $132^{\circ}$ to $172^{\circ}$ (average $152.5^{\circ}$ ); average digit divarication of digit I and II is $80.9^{\circ}$, which is approximately $9^{\circ}$ greater than that between II and III $\left(71.9^{\circ}\right)$. The metacarpophalangeal joint depression is shallower than the digital impressions. There is no indication of digit impression IV, nor of webbing between the digits (Fig. 4A).

The pes prints are triangular, elongate and fully plantigrade. They are tetradactyl with anterior claw marks, making a fork with 

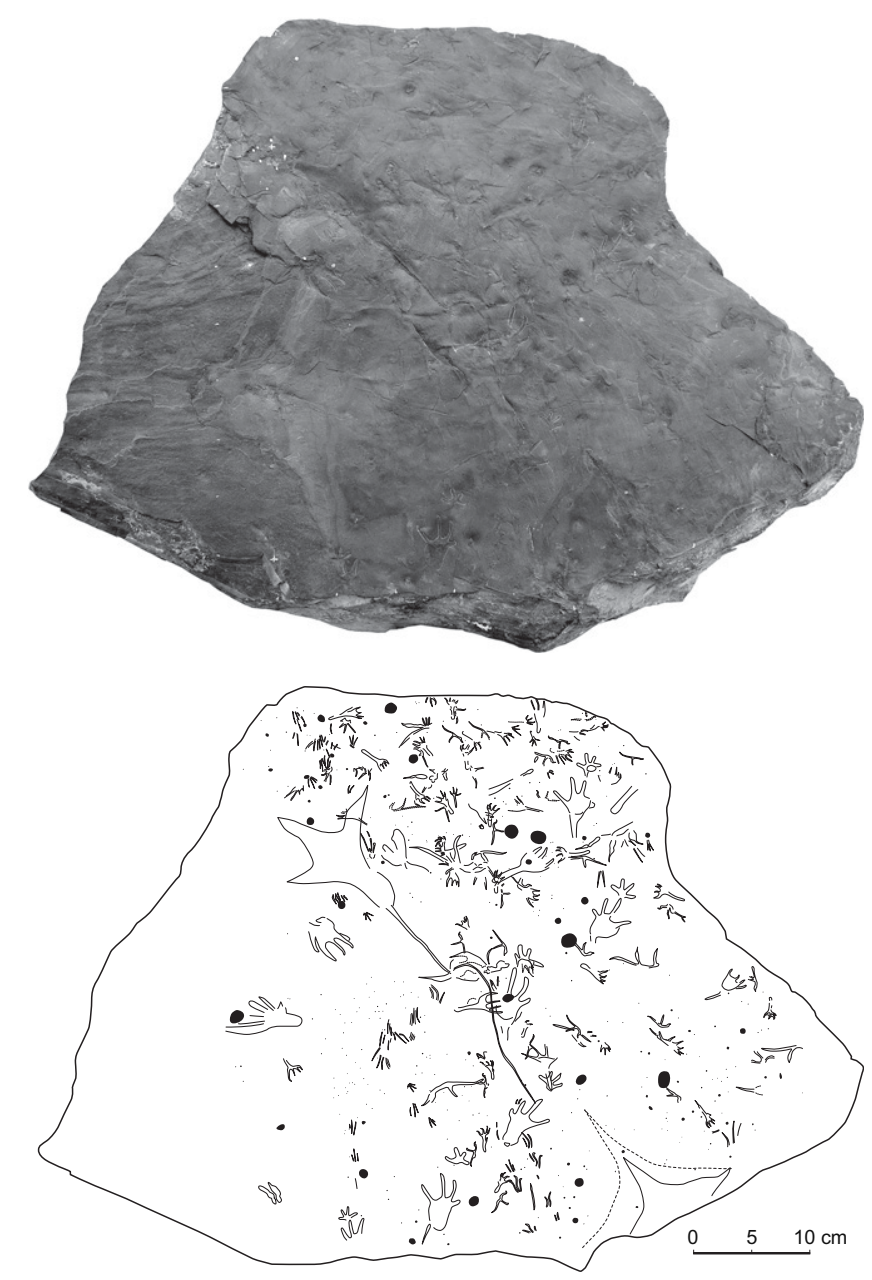

Fig. 3. Photograph and drawing of the block containing various trace fossils (FPDMF022-1). Black dots are feeding marks.

four points in shape. The claw marks are curved laterally and the divarication of digit I and II impressions are usually smaller than that between II and III, III and IV. The digit I imprint is the shortest and other three digit imprints are roughly subequal in length (Table 1 ). The interdigital webbing extends from the metatarso-phalangeal joint near to the bases of the claws. The metatarsals are long and elongate, diverging moderately like the handle of a fork, which are always longer than the digits. The metatarso-phalangeal joint part is usually wider and deeper than the heel of the pes. There is no preservation of an impression formed by a fifth metatarsal (Fig. 4B).

Among 84 pterosaur tracks, five trackways are recognizable except for 20 isolated prints. Five trackways are oriented in an apparently random pattern, including some overstepping imprints (Fig. 5). The high density of tracks suggest gregarious behavior (Mickelson et al., 2004), but the random orientation of trackways does not show that they were moving to the same direction in herd. Instead, many small round depressions on the slab possibly suggest that this group of pterosaur individuals was feeding together (Fig. 3).

All of the trackways show a clear quadrupedal gait pattern comprising manus and pes prints easily recognized by the distinctive print morphology (Fig. 6). In these trackways, the pes print is anterior to the manus print and the latter is located further from the mid-line than the former. Namely, the manus gait-width is wider than the pes gait-width as seen in the typical pterosaur ichnotaxa such as Pteraichnus saltwashensis (Stokes, 1957) and $P$. koreanensis (Lee et al., 2008). Both manus and pes prints show outward rotation.

The trackway A is the longest one among preserved five trackways, comprising 15 manus-pes print sets ( 7 left and 8 right) although left 3rd, right 2 nd and 4 th sets are not preserved. The average manus length and width is $20.0 \mathrm{~mm}$ and $8.8 \mathrm{~mm}$, respectively. The average length of manus' digit I, II, III is $7.6 \mathrm{~mm}, 7.9 \mathrm{~mm}$, and $12.2 \mathrm{~mm}$, respectively. The average divarication of digit I and III impressions is $166.4^{\circ}$ and average digit divarication of digit I and II $\left(83.2^{\circ}\right)$ is slightly higher than that between II and III $\left(81.7^{\circ}\right)$. The average manus stride length is $55.9 \mathrm{~mm}$ and the average pace length is $47.4 \mathrm{~mm}$ with the $36.5^{\circ}$ pace angulation. The average length and width of the pes impressions is $19.4 \mathrm{~mm}$ and $10.5 \mathrm{~mm}$, respectively. The average pes stride length is $53.9 \mathrm{~mm}$ and the average pace length is $44.9 \mathrm{~mm}$ with the $35.8^{\circ}$ pace angulation. Hence, the manus is almost same as the pes in length but the stride, pace and pace angulation of the pes are slightly smaller than those of the manus. This trackway shows that the pterosaur walked with a normal gait without any big action. The manus-gait width shows a clear "narrow gauge" pattern.

The trackway B consists of eight consecutive manus-pes sets with three pes-only prints. The average manus length and width is $23.5 \mathrm{~mm}$ and $8.8 \mathrm{~mm}$, respectively. The average length of manus' digit I, II, III is $8.3 \mathrm{~mm}, 8.7 \mathrm{~mm}$, and $15.3 \mathrm{~mm}$, respectively. The average divarication of digit I and III impressions is $136.0^{\circ}$ and average digit divarication of digit I and II $\left(80.7^{\circ}\right)$ is much higher than that between II and III $\left(55.3^{\circ}\right)$. The average manus stride length is $90.6 \mathrm{~mm}$ and the average pace length is $64.0 \mathrm{~mm}$ with the $44.6^{\circ}$ pace angulation. The average length and width of the pes impressions is $23.2 \mathrm{~mm}$ and $11.2 \mathrm{~mm}$, respectively. The average pes stride length is $91.3 \mathrm{~mm}$ and the average pace length is $61.8 \mathrm{~mm}$ with the $49.3^{\circ}$ pace angulation. Therefore, the manus is almost same as the pes in length but the stride and pace angulation of the pes are slightly bigger than those of the manus, but the pace of the pes is smaller than that of the manus.

The trackway C consists of six manus-pes print sets ( 3 left and 3 right) although right 1 st set and right 3rd pes are not preserved. The average manus length and width is $27.8 \mathrm{~mm}$ and $10.7 \mathrm{~mm}$, respectively. The average length of manus' digit I, II, III is $10.5 \mathrm{~mm}$, $10.4 \mathrm{~mm}$, and $18.1 \mathrm{~mm}$, respectively. The average divarication of digit I and III impressions is $132.7^{\circ}$ and average digit divarication of digit I and II $\left(72.7^{\circ}\right)$ is much higher than that between II and III $\left(60.0^{\circ}\right)$. The average manus stride length is $99.3 \mathrm{~mm}$ and the average pace length is $70.6 \mathrm{~mm}$ with the $97.7^{\circ}$ pace angulation. The average length and width of the pes impressions is $27.0 \mathrm{~mm}$ and $12.3 \mathrm{~mm}$, respectively. The average pes stride length is $97.5 \mathrm{~mm}$ and the average pace length is $65.7 \mathrm{~mm}$ with the $103.6^{\circ}$ pace angulation. The manus is almost same as the pes in length but the stride and pace of the manus are slightly bigger than those of the pes, but the pace angulation of the pes is slightly bigger than that of the manus.

The trackway D consists of five manus-pes print sets ( 2 left and 3 right) although left 1st manus and right 3rd pes imprints are not preserved. The average manus length and width is $21.6 \mathrm{~mm}$ and $9.1 \mathrm{~mm}$, respectively. The average length of manus' digit I, II, III is $9.3 \mathrm{~mm}, 7.8 \mathrm{~mm}$, and $12.2 \mathrm{~mm}$, respectively. The average divarication of digit I and III impressions ranges $169.6^{\circ}$ and average digit divarication of digit I and II $\left(87.2^{\circ}\right)$ is slightly higher than that between II and III $\left(82.4^{\circ}\right)$. The average manus stride length is $78.0 \mathrm{~mm}$ and the average pace length is $49.0 \mathrm{~mm}$ with the $97.7^{\circ}$ pace angulation. The average length and width of the pes impressions is $21.4 \mathrm{~mm}$ and $10.3 \mathrm{~mm}$, respectively. The average pes stride length is $70.8 \mathrm{~mm}$ and the average pace length is $42.5 \mathrm{~mm}$ with the $111.5^{\circ}$ pace angulation. The manus is almost same as the pes in 

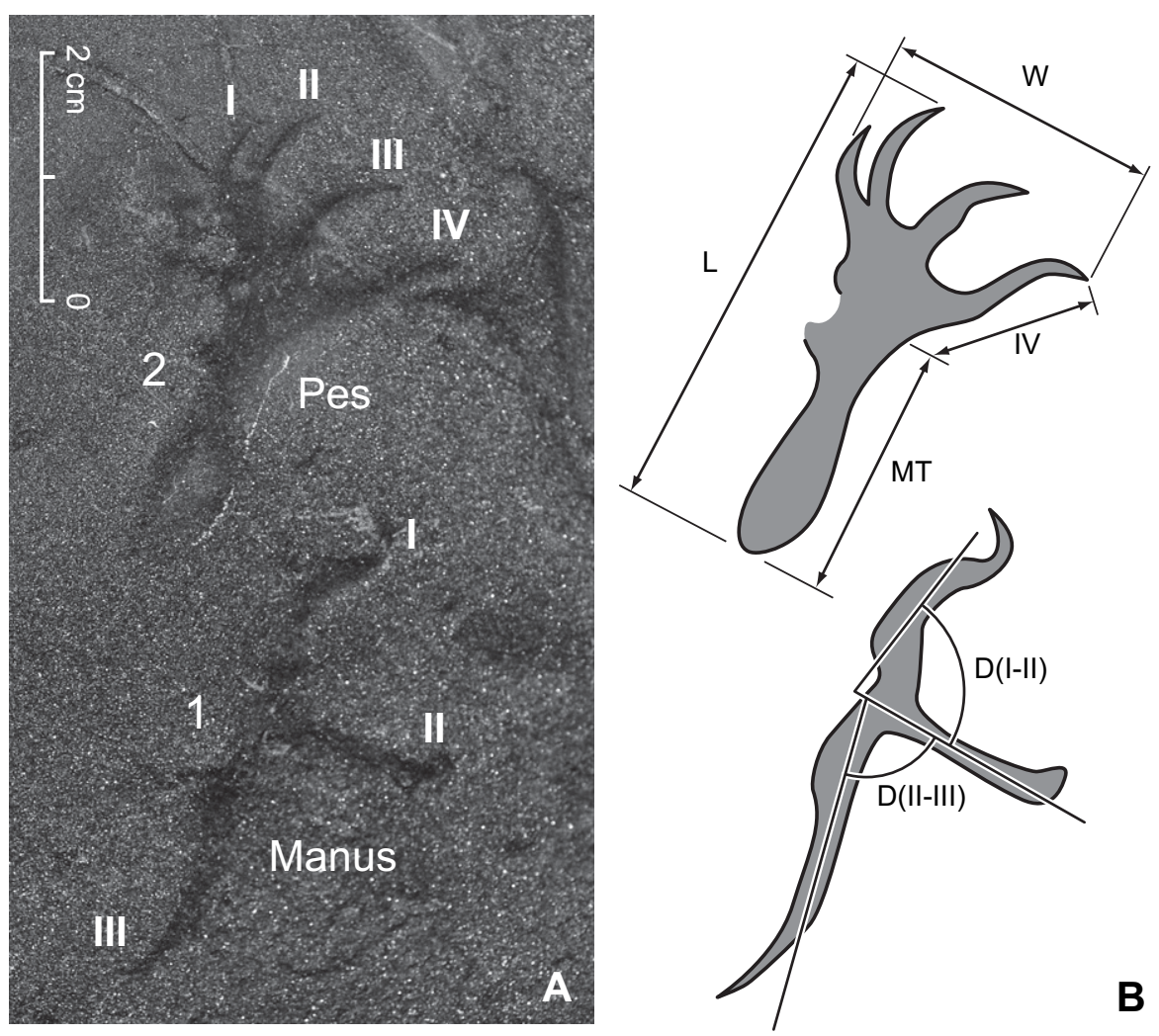

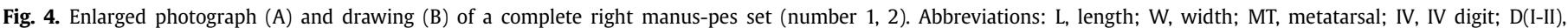
divarication between digit I and II; D(II-III), divarication between digit II and III.

length but the stride and pace of the manus are slightly bigger than those of the pes, but the pace angulation of the pes is slightly bigger than that of the manus.

The trackway E consists of only two right manus-pes print sets without left ones, so it lacks a complete locomotor cycle. However, we interpret that they comprise a trackway based on the trackway pattern and regulation of manus-pes print sets. The average manus length and width is $19.8 \mathrm{~mm}$ and $7.8 \mathrm{~mm}$, respectively. The average length of manus' digit I, II, III is $8.2 \mathrm{~mm}, 6.4 \mathrm{~mm}$, and $11.4 \mathrm{~mm}$, respectively. The average divarication of digit I and III impressions ranges $172.3^{\circ}$ and average digit divarication of digit I and II $\left(70.1^{\circ}\right)$ is lower than that between II and III $\left(102.2^{\circ}\right)$. The manus stride length is $66.5 \mathrm{~mm}$, but pace length and pace angulation cannot be calculated because the left manus-pes print set is not preserved. The average length and width of the pes impressions is $18.2 \mathrm{~mm}$ and $10.7 \mathrm{~mm}$, respectively. The pes stride length is $63.5 \mathrm{~mm}$. The manus is almost same as the pes in length and stride.

Discussion. Five ichnospecies of Pterachnus were known before including the type ichnospecies, P. saltwashensis (Stokes, 1957; Lockley et al., 1995; Calvo and Lockley, 2001; Fuentes Vidarte et al., 2004a; Lee et al., 2008). The first discovered pterosaur trackway, $P$. saltwashensis, was described from the Upper Jurassic Morrison Formation, which is quite different from Pteraichnus nipponensis in size and morphology. P. nipponensis is approximately three times smaller than $P$. saltwashensis where the manus and pes length is $82.6 \mathrm{~mm}$ and $76.2 \mathrm{~mm}$, respectively. P. nipponensis has longer and more elongate metatarsal impression than $P$. saltwashensis. The digit I imprint of the manus is the shortest in P. saltwashensis, but it is almost same as the digit II in P. nipponensis. The digit I imprint is oriented laterally in the former so that the divarication between the digit I and III is much smaller than that of the latter.
Lockley et al. (1995) reported Pteraichnus stokesi from the Sundance Formation (Middle to Upper Jurassic), which was later regarded as a junior synonym of $P$. saltwashensis (Bennett, 1997; Billon-Bruyat and Mazin, 2003). However, Sánchez-Hernández et al. (2009) recently resurrected it as a valid ichnotaxon, admitting the original diagnostic characters are valid. One key character of $P$. stokesi is that the manus $(70 \mathrm{~mm})$ is shorter than the pes (90 $\mathrm{mm}$ ), whereas in P. saltwashensis the opposite is the case. Apparently, P. nipponensis differs from $P$. stokesi in details of track morphology as well as size. In addition, the long time interval and geographic distance between the Jurassic Morrison and Sundance Formations in North America and the Lower Cretaceous Kitadani Formation in Japan is unlikely to reflect the same ichnospecies.

Billon-Bruyat and Mazin (2003) reassessed four pterosaur ichnospecies (P. palacieisaenzi, P. cidacoi, P. manueli, and P. vetustior) referred to Pteraichnus from the Lower Cretaceous beds in the Oncala Group (Berriasian), Soria, Spain and regarded them as nomina nuda because they were unavailable according to the ICZN and their minor differences were attributed to intra-ichnospecific variability (Pascual Arribas and Sanz Perez, 2000; Fuentes Vidarte, 2001; Meijide Calvo, 2001; Meijide Fuentes, 2001). Since then, Fuentes Vidarte et al. (2004a,b) described two new ichnospecies (P. longipodus and P. parvus) in the Oncala Group along with the resurrection of $P$. manueli and $P$. vetustior previously regarded as nomina nuda. Six ichnospecies of Pteraichnus above from the Camerous Basin, Soria were recently reexamined taxonomically (Sánchez-Hernández et al., 2009). They regarded only P. longipodus and $P$. parvus are valid ichnotaxa.

P. longipodus is 1.5 times bigger than P. nipponensis in size and shows low divarication between manus' digit I and III relative to the latter. And the pes imprint has an impression formed by a fifth metatarsal (Fuentes Vidarte et al., 2004a, fig. 7). P. parvus is the 
Table 1

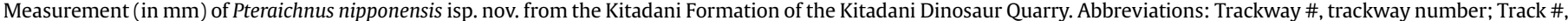

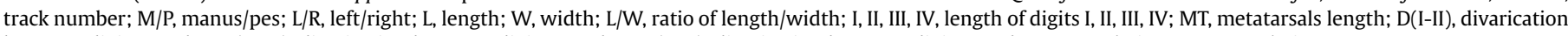
between digits I and II; D(II-III), divarication between digits II and III; D(I-III), divarication between digits I and III; P angulation, pace angulation.

\begin{tabular}{|c|c|c|c|c|c|c|c|c|c|c|c|c|c|c|c|c|c|}
\hline Trackway \# & Track \# & $\mathrm{M} / \mathrm{P}$ & $L / R$ & $\mathrm{~L}$ & W & $\mathrm{L} / \mathrm{W}$ & I & II & III & IV & MT & $\mathrm{D}(\mathrm{I}-\mathrm{II})$ & D(II-III) & $\mathrm{D}(\mathrm{I}-\mathrm{III})$ & Stride & Pace & $\mathrm{P}$ angulation \\
\hline \multirow[t]{24}{*}{ A } & 1 & $M$ & $\mathrm{R}$ & 22.25 & 7.84 & 2.84 & 7.03 & 6.97 & 13.37 & - & - & 82.0 & 77.4 & 159.4 & - & - & - \\
\hline & 2 & $\mathrm{P}$ & $\mathrm{R}$ & 19.2 & 12.09 & 1.59 & 5.27 & 6.64 & 5.39 & 4 & 12.96 & - & - & - & - & - & - \\
\hline & 3 & M & $\mathrm{L}$ & 18.48 & 8.28 & 2.23 & 5.91 & 7.24 & 11.87 & - & - & 72.3 & 84.9 & 157.2 & - & 46.90 & - \\
\hline & 4 & $\mathrm{P}$ & $\mathrm{L}$ & 21.12 & 11.03 & 1.91 & 4.99 & 5.53 & 5.02 & 5.38 & 12.92 & - & - & - & - & 41.63 & - \\
\hline & 5 & M & $\mathrm{L}$ & 21.42 & 8.73 & 2.45 & 7.48 & 7.48 & 13.18 & - & - & 70.8 & 81.0 & 151.8 & 59.78 & - & - \\
\hline & 6 & $\mathrm{P}$ & $\mathrm{L}$ & 18.54 & 8.95 & 2.07 & 4.4 & 4.2 & 4.4 & 4.78 & 11.51 & - & - & - & 59.04 & - & - \\
\hline & 7 & M & $\mathrm{R}$ & 22.59 & 8.33 & 2.71 & 9.68 & 7.31 & 12.06 & - & - & 90.6 & 79.8 & 170.4 & - & 49.87 & - \\
\hline & 8 & $\mathrm{P}$ & $\mathrm{R}$ & 19.46 & 11.71 & 1.66 & 3.86 & 4.37 & 5.01 & 5.32 & 9.18 & - & - & - & - & 46.57 & - \\
\hline & 9 & M & $\mathrm{L}$ & 21.11 & 9.36 & 2.26 & 9.2 & 7.7 & 12.35 & - & - & 84.1 & 82.7 & 166.8 & - & - & - \\
\hline & 10 & $\mathrm{P}$ & $\mathrm{L}$ & 21.26 & 9.28 & 2.29 & 4.2 & 4.72 & 4.73 & 4.92 & 12.69 & - & - & - & - & - & - \\
\hline & 11 & M & $\mathrm{R}$ & 21.59 & 9.47 & 2.28 & 7.29 & 7.3 & 10.97 & - & - & 91.7 & 94.9 & 186.6 & - & 53.74 & 39.07 \\
\hline & 12 & $\mathrm{P}$ & $\mathrm{R}$ & 17.28 & 9.54 & 1.81 & 3.8 & 4.47 & 3.58 & 5.05 & 11.91 & - & - & - & - & 46.78 & 42.36 \\
\hline & 13 & M & $\mathrm{L}$ & 20.51 & 8.87 & 2.31 & 7.19 & 8.93 & 15.04 & - & - & - & - & - & 63.88 & 47.30 & 35.68 \\
\hline & 14 & $\mathrm{P}$ & $\mathrm{L}$ & 20.1 & 8.23 & 2.44 & - & - & - & - & - & - & - & - & 67.04 & 52.53 & 33.97 \\
\hline & 15 & M & $\mathrm{R}$ & 21.16 & 9.01 & 2.35 & 8.89 & 8.97 & 11.33 & - & - & 113.6 & 79.5 & 193.1 & 55.34 & 47.59 & 33.88 \\
\hline & 16 & $\mathrm{P}$ & $\mathrm{R}$ & 18.46 & 11.69 & 1.58 & 4.52 & 3.89 & 4 & 4.02 & 12.21 & - & - & - & 58.58 & 52.33 & 26.15 \\
\hline & 17 & M & $\mathrm{L}$ & - & 8.93 & - & - & 8.93 & 10.72 & - & - & - & 78.6 & - & 52.52 & 46.62 & 38.96 \\
\hline & 18 & $\mathrm{P}$ & $\mathrm{L}$ & 19.27 & 11.15 & 1.73 & 4.09 & 4.42 & 4.2 & 4.24 & 13.67 & - & - & - & 42.30 & 40.70 & 40.65 \\
\hline & 19 & $\mathrm{M}$ & $\mathrm{R}$ & 18.61 & 9.15 & 2.03 & 7.08 & 7.66 & 12.12 & - & - & - & 85.0 & - & 54.61 & 39.82 & 35.41 \\
\hline & 20 & $\mathrm{P}$ & $\mathrm{R}$ & 19.36 & 11.06 & 1.75 & 3.44 & 4.2 & 4.54 & 4.51 & 13.21 & - & - & - & 56.21 & 45.42 & 38.66 \\
\hline & 21 & M & $\mathrm{L}$ & 11.82 & 7.9 & 1.50 & 6.62 & 8.12 & 11.85 & - & - & 60.3 & 85.4 & 145.7 & 50.08 & 46.15 & 35.73 \\
\hline & 22 & $\mathrm{P}$ & $\mathrm{L}$ & - & 10.35 & - & - & - & - & 5.26 & - & - & - & - & 51.26 & 35.73 & 32.78 \\
\hline & 23 & M & $\mathrm{R}$ & 21.33 & 9.33 & 2.29 & 7.63 & 8.6 & 11.83 & - & - & - & 69.5 & - & 55.23 & 48.38 & - \\
\hline & 24 & $\mathrm{P}$ & $\mathrm{R}$ & 18.89 & 11.12 & 1.70 & 3.45 & 3.74 & 3.86 & 3.87 & 13.15 & - & - & - & 42.83 & 42.66 & - \\
\hline Average manus & & & & 20.08 & 8.77 & 2.30 & 7.64 & 7.93 & 12.22 & & & 83.18 & 81.70 & 166.38 & 55.92 & 47.37 & 36.45 \\
\hline Average pes & & & & 19.36 & 10.52 & 1.87 & 3.82 & 4.62 & 4.47 & 4.67 & 12.34 & & & & 53.89 & 44.92 & 35.76 \\
\hline \multirow[t]{19}{*}{ B } & 25 & $\mathrm{P}$ & $\mathrm{L}$ & 25.73 & 10.57 & 2.43 & 5.57 & 4.46 & 4.43 & 5.18 & 17.6 & - & - & - & - & - & - \\
\hline & 26 & $\mathrm{P}$ & $\mathrm{R}$ & 23.98 & 12.99 & 1.85 & 5.9 & 6.21 & 5.87 & 6.6 & 15.24 & - & - & - & - & - & - \\
\hline & 27 & $\mathrm{P}$ & $\mathrm{L}$ & 24.02 & 9.98 & 2.41 & 5.44 & 5.87 & 6.48 & - & 14.81 & - & - & - & - & 57.43 & - \\
\hline & 28 & M? & $\mathrm{R}$ & - & - & - & - & - & - & - & - & - & - & - & - & - & - \\
\hline & 29 & $\mathrm{P}$ & $\mathrm{R}$ & - & 11.27 & - & 6.77 & 4.63 & 6.44 & 9.4 & - & - & - & - & 74.21 & 57.98 & 38.26 \\
\hline & 30 & M & $\mathrm{L}$ & - & - & - & 5.53 & - & - & - & - & 79.5 & 58.9 & 138.4 & - & 62.70 & 44.98 \\
\hline & 31 & $\mathrm{P}$ & $\mathrm{L}$ & 19.25 & 8.01 & 2.40 & - & - & - & - & - & - & - & - & 77.72 & 67.01 & 49.87 \\
\hline & 32 & M & $\mathrm{R}$ & 21.63 & 8.86 & 2.44 & 8.59 & 9.12 & 12.93 & - & - & 71.0 & 73.5 & 144.5 & 83.00 & 54.43 & 40.27 \\
\hline & 33 & $\mathrm{P}$ & $\mathrm{R}$ & 19.79 & - & - & - & - & - & - & - & - & - & - & 97.53 & 60.43 & 47.90 \\
\hline & 34 & M & $\mathrm{L}$ & 24.8 & 8.42 & 2.95 & 8.6 & 8.81 & 17.06 & - & - & 72.2 & 49.4 & 121.6 & 80.20 & 68.53 & 45.39 \\
\hline & 35 & $\mathrm{P}$ & $\mathrm{L}$ & 25.41 & 12.56 & 2.02 & 4.13 & 4.95 & 4.84 & 4.8 & 19.17 & - & - & - & 90.97 & 62.18 & 52.88 \\
\hline & 36 & $\mathrm{M}$ & $\mathrm{R}$ & 26.73 & 7.94 & 3.37 & 9.35 & 8.45 & 19.82 & - & - & 84.9 & 60.2 & 145.1 & 94.85 & 64.67 & 41.94 \\
\hline & 37 & $\mathrm{P}$ & $\mathrm{R}$ & 24.58 & 13.01 & 1.89 & 4.85 & 4.09 & 4.86 & 5.2 & 15.63 & - & - & - & 98.42 & 61.26 & 48.73 \\
\hline & 38 & M & $\mathrm{L}$ & 22.49 & 10.39 & 2.16 & 8.23 & 8.92 & 14.06 & - & - & 72.8 & 67.1 & 139.9 & 91.68 & 72.25 & 50.40 \\
\hline & 39 & $\mathrm{P}$ & $\mathrm{L}$ & 23.97 & 12.06 & 1.99 & 3.86 & 3.99 & 4.89 & 4.85 & 19.43 & - & - & - & 91.00 & 59.81 & 58.08 \\
\hline & 40 & M & $\mathrm{R}$ & 23.26 & 8.75 & 2.66 & 9.03 & 8.01 & 12.52 & - & - & 86.9 & 40.3 & 127.2 & 103.27 & 61.49 & - \\
\hline & 41 & $\mathrm{P}$ & $\mathrm{R}$ & 24.24 & 10.89 & 2.23 & - & 4.75 & 4.76 & 4.79 & 17.59 & - & - & - & 108.99 & 68.49 & - \\
\hline & 42 & M & $\mathrm{L}$ & 22.25 & 8.22 & 2.71 & 8.77 & - & - & - & - & 97.5 & 37.8 & 135.3 & - & - & - \\
\hline & 43 & $\mathrm{P}$ & $\mathrm{L}$ & 21.1 & 10.6 & 1.99 & - & - & - & - & - & - & - & - & - & - & - \\
\hline Average manus & & & & 23.53 & 8.76 & 2.71 & 8.30 & 8.66 & 15.28 & & & 80.69 & 55.31 & 136.00 & 90.60 & 64.01 & 44.59 \\
\hline Average pes & & & & 23.21 & 11.19 & 2.13 & 5.22 & 4.87 & 5.32 & 6.77 & 17.07 & & & & 91.26 & 61.82 & 49.29 \\
\hline \multirow[t]{9}{*}{ C } & 44 & M & $\mathrm{L}$ & 25.8 & 12.63 & 2.04 & 11.31 & 11.88 & 17.74 & - & - & 74.4 & 74.6 & 149.0 & - & - & - \\
\hline & 45 & $\mathrm{P}$ & $\mathrm{L}$ & 27.59 & 13.31 & 2.07 & 5.69 & 6.17 & 8.12 & 9.05 & 20.33 & - & - & - & - & - & - \\
\hline & 46 & M & $\mathrm{L}$ & 24.97 & 10.96 & 2.28 & 9.96 & 10.58 & 15.51 & - & - & 91.5 & 62.2 & 153.7 & 84.05 & - & - \\
\hline & 47 & $\mathrm{P}$ & $\mathrm{L}$ & 25.75 & 15.8 & 1.63 & 8.17 & 9.08 & 8.75 & 10.18 & 16.43 & - & - & - & 91.30 & - & - \\
\hline & 48 & M & $\mathrm{R}$ & 25.39 & 10.43 & 2.43 & 10.07 & 9.84 & 18.36 & - & - & 51.8 & 75.9 & 127.7 & - & 60.47 & 83.74 \\
\hline & 49 & $\mathrm{P}$ & $\mathrm{R}$ & 26.72 & 11.88 & 2.25 & - & - & 7.46 & 7.48 & 17.54 & - & - & - & - & 54.65 & 103.15 \\
\hline & 50 & M & $\mathrm{L}$ & 32.04 & 10.31 & 3.11 & 9.58 & 9.82 & 20.66 & - & - & 98.3 & 51.8 & 150.1 & 88.22 & 71.17 & 111.56 \\
\hline & 51 & $\mathrm{P}$ & $\mathrm{L}$ & 27.72 & 8.18 & 3.39 & 6.39 & 6.34 & - & - & - & - & - & - & 103.72 & 76.60 & - \\
\hline & 52 & M & $\mathrm{R}$ & 31.02 & 9.32 & 3.33 & 11.55 & 9.94 & 18.19 & - & - & 47.6 & 35.3 & 82.9 & 125.63 & 80.62 & - \\
\hline Average manus & & & & 27.84 & 10.73 & 2.64 & 10.49 & 10.41 & 18.09 & & & 72.71 & 59.96 & 132.67 & 99.30 & 70.75 & 97.65 \\
\hline Average pes & & & & 26.95 & 12.29 & 2.34 & 6.75 & 7.20 & 8.11 & 8.90 & 18.10 & & & & 97.51 & 65.63 & 103.15 \\
\hline \multirow[t]{8}{*}{ D } & 53 & M & $\mathrm{R}$ & 23.28 & 9.39 & 2.48 & 10.52 & 7.98 & 13.43 & - & - & 99.1 & 76.1 & 175.2 & - & - & - \\
\hline & 54 & $\mathrm{P}$ & $\mathrm{R}$ & 21.2 & - & - & - & - & 6.71 & 8.54 & 12.35 & - & - & - & - & - & - \\
\hline & 55 & $\mathrm{P}$ & $\mathrm{L}$ & - & - & - & 5.85 & 6.75 & 5.02 & 4.05 & - & - & - & - & - & 45.07 & 119.35 \\
\hline & 56 & M & $\mathrm{R}$ & 20.26 & 9.62 & 2.11 & 8.09 & 8.16 & 10.99 & - & - & 81.3 & 76.4 & 157.6 & 82.18 & - & - \\
\hline & 57 & $\mathrm{P}$ & $\mathrm{R}$ & 21.2 & 9.48 & 2.24 & 4.43 & 4.48 & 5.13 & 6.42 & 14.03 & - & - & - & 76.73 & 43.82 & 103.53 \\
\hline & 58 & M & $\mathrm{L}$ & 21.71 & 8.2 & 2.65 & 8.82 & 8.52 & 11.98 & - & - & 83.9 & 75.7 & 159.6 & & 46.52 & 97.65 \\
\hline & 59 & $\mathrm{P}$ & $\mathrm{L}$ & 21.67 & 11.1 & 1.95 & 3.91 & 4.61 & 4.68 & 4.76 & 13.47 & - & - & - & 64.80 & 38.57 & - \\
\hline & 60 & M & $\mathrm{R}$ & 21.31 & 9.06 & 2.35 & 9.56 & 6.54 & 12.56 & - & - & 84.5 & 101.6 & 186.2 & 73.74 & 51.36 & - \\
\hline Average manus & & & & 21.64 & 9.07 & 2.40 & 9.25 & 7.80 & 12.24 & & & 87.20 & 82.44 & 169.64 & 77.96 & 48.94 & 97.65 \\
\hline Average pes & & & & 21.36 & 10.29 & 2.09 & 4.73 & 5.28 & 5.39 & 5.94 & 13.28 & & & & 70.77 & 42.49 & 111.44 \\
\hline \multirow[t]{2}{*}{ E } & 61 & M & $\mathrm{R}$ & 19.82 & 7.03 & 2.82 & 8.14 & 5.82 & 11.08 & - & - & 54.8 & 99.2 & 154.0 & - & - & - \\
\hline & 62 & $\mathrm{P}$ & $\mathrm{R}$ & 18.22 & 10.68 & 1.71 & 5.24 & 4.91 & 5.18 & 5.24 & 12.61 & - & - & - & - & - & - \\
\hline
\end{tabular}


Table 1 (continued)

\begin{tabular}{|c|c|c|c|c|c|c|c|c|c|c|c|c|c|c|c|c|c|}
\hline Trackway \# & Track \# & $\mathrm{M} / \mathrm{P}$ & $L / R$ & $\mathrm{~L}$ & W & $\mathrm{L} / \mathrm{W}$ & I & II & III & IV & MT & $\mathrm{D}(\mathrm{I}-\mathrm{II})$ & $\mathrm{D}$ (II-III) & $\mathrm{D}(\mathrm{I}-\mathrm{III})$ & Stride & Pace & $\mathrm{P}$ angulation \\
\hline & 63 & $\mathrm{M}$ & $\mathrm{R}$ & 19.79 & 8.61 & 2.30 & 8.19 & 7.05 & 11.68 & - & - & 85.4 & 105.1 & 190.5 & 66.45 & - & - \\
\hline & 64 & $\mathrm{P}$ & $\mathrm{R}$ & - & - & - & 8.22 & 5.54 & - & - & - & - & - & - & 63.50 & - & - \\
\hline Average manus & & & & 19.81 & 7.82 & 2.56 & 8.17 & 6.44 & 11.38 & & & 70.08 & 102.17 & 172.25 & 66.45 & & \\
\hline Average pes & & & & 18.22 & 10.68 & 1.71 & 6.73 & 5.23 & 5.18 & 5.24 & 12.61 & & & & 63.50 & & \\
\hline \multirow[t]{20}{*}{ Isolated tracks } & 65 & M & $\mathrm{L}$ & 54.13 & 19.21 & 2.82 & 17.64 & 17.18 & 36.6 & - & - & 86.1 & 42.1 & 128.2 & - & - & - \\
\hline & 66 & $\mathrm{P}$ & $\mathrm{L}$ & 41.28 & 23.04 & 1.79 & 8.26 & 8.59 & 8.7 & 9.2 & 28.3 & - & - & - & - & - & - \\
\hline & 67 & $\mathrm{P}$ & $\mathrm{R} ?$ & 41.38 & 19.01 & 2.18 & 8.08 & 8.97 & 9 & 9.03 & 33.1 & - & - & - & - & & \\
\hline & 68 & M & $\mathrm{L}$ & 42.83 & 17.74 & 2.41 & 28 & 16.41 & 28.55 & - & - & 97.5 & 50.7 & 148.3 & & - & - \\
\hline & 69 & $\mathrm{P}$ & $\mathrm{L}$ & 38.28 & 24.21 & 1.58 & 6.85 & 5.75 & 8.47 & 7.84 & 32.24 & - & - & - & & & - \\
\hline & 70 & M & $\mathrm{R}$ & - & 15.68 & - & - & 13.99 & 28.47 & - & - & - & 57.6 & - & - & & - \\
\hline & 71 & $\mathrm{P}$ & $\mathrm{R}$ & 22.69 & 13.73 & 1.65 & 3.83 & 4.76 & 5.4 & 6.07 & 12.6 & - & - & - & - & - & - \\
\hline & 72 & $\mathrm{P}$ & $\mathrm{R} ?$ & 56.32 & 21.89 & 2.57 & 10.16 & 12.37 & 13.58 & 15 & 34.59 & - & - & - & - & - & - \\
\hline & 73 & $P$ & $\mathrm{R}$ & 18.74 & 11.01 & 1.70 & 6.11 & 4.53 & 3.48 & 3.35 & 10.96 & - & - & - & - & - & - \\
\hline & 74 & M & $\mathrm{R}$ & 21.87 & - & - & 10.71 & - & 11.28 & - & - & 101.6 & 55.6 & 157.2 & - & - & - \\
\hline & 75 & $\mathrm{M}$ & $\mathrm{R}$ & 54.78 & 24.51 & 2.24 & 19.46 & 34.1 & 37.32 & - & - & 127.8 & 43.3 & 171.1 & - & - & - \\
\hline & 76 & M & $\mathrm{L}$ & 69.21 & 28.89 & 2.40 & 27.8 & 26.49 & 45.77 & - & - & 91.2 & 54.0 & 145.2 & - & - & - \\
\hline & 77 & $\mathrm{P}$ & $\mathrm{R}$ ? & 30.23 & 11.56 & 2.62 & 5.38 & 4.85 & 6.54 & 5.16 & 19.54 & - & - & - & - & - & - \\
\hline & 78 & $P$ & $\mathrm{R} ?$ & - & 9.56 & - & - & 7.4 & 8.47 & 5.47 & - & - & - & - & - & - & - \\
\hline & 79 & $\mathrm{P}$ & $?$ & - & - & - & - & - & - & - & - & - & - & - & - & - & - \\
\hline & 80 & $\mathrm{P}$ & $\mathrm{R}$ ? & 13.02 & 8.92 & 1.46 & 4.84 & 5.62 & 6.08 & 4.4 & 6.61 & - & - & - & - & - & - \\
\hline & 81 & $\mathrm{P}$ & L? & 17.76 & 9.57 & 1.86 & 4.97 & 5.36 & 6.27 & 3.89 & 10.49 & - & - & - & - & - & - \\
\hline & 82 & $\mathrm{P}$ & L? & 42.33 & 30.3 & 1.40 & - & 12.44 & 14.37 & 14.48 & 21.92 & - & - & - & - & - & - \\
\hline & 83 & M & $\mathrm{L}$ & 58.19 & 15.17 & 3.84 & 30.4 & 13.28 & 29.9 & - & - & 95.4 & 59.0 & 154.4 & - & - & - \\
\hline & 84 & $\mathrm{P}$ & $\mathrm{R}$ ? & - & 14.72 & - & 6.19 & 6.52 & 7.46 & 12.04 & - & - & - & - & - & - & - \\
\hline
\end{tabular}

smallest pterosaur track among four ichnospecies of the Oncala Group (Fuentes Vidarte et al., 2004b). Its average manus and pes length is $23 \mathrm{~mm}$ and $15 \mathrm{~mm}$, respectively. The size, shape and angulation between digits of manus imprint are similar to those of
P. nipponensis. But, the pes of $P$. parvus has a very short metatarsal impression. The general morphology of the metatarsal impression is almost rectangular in shape with wide heel impression (Fuentes Vidarte et al., 2004b, fig. 6).

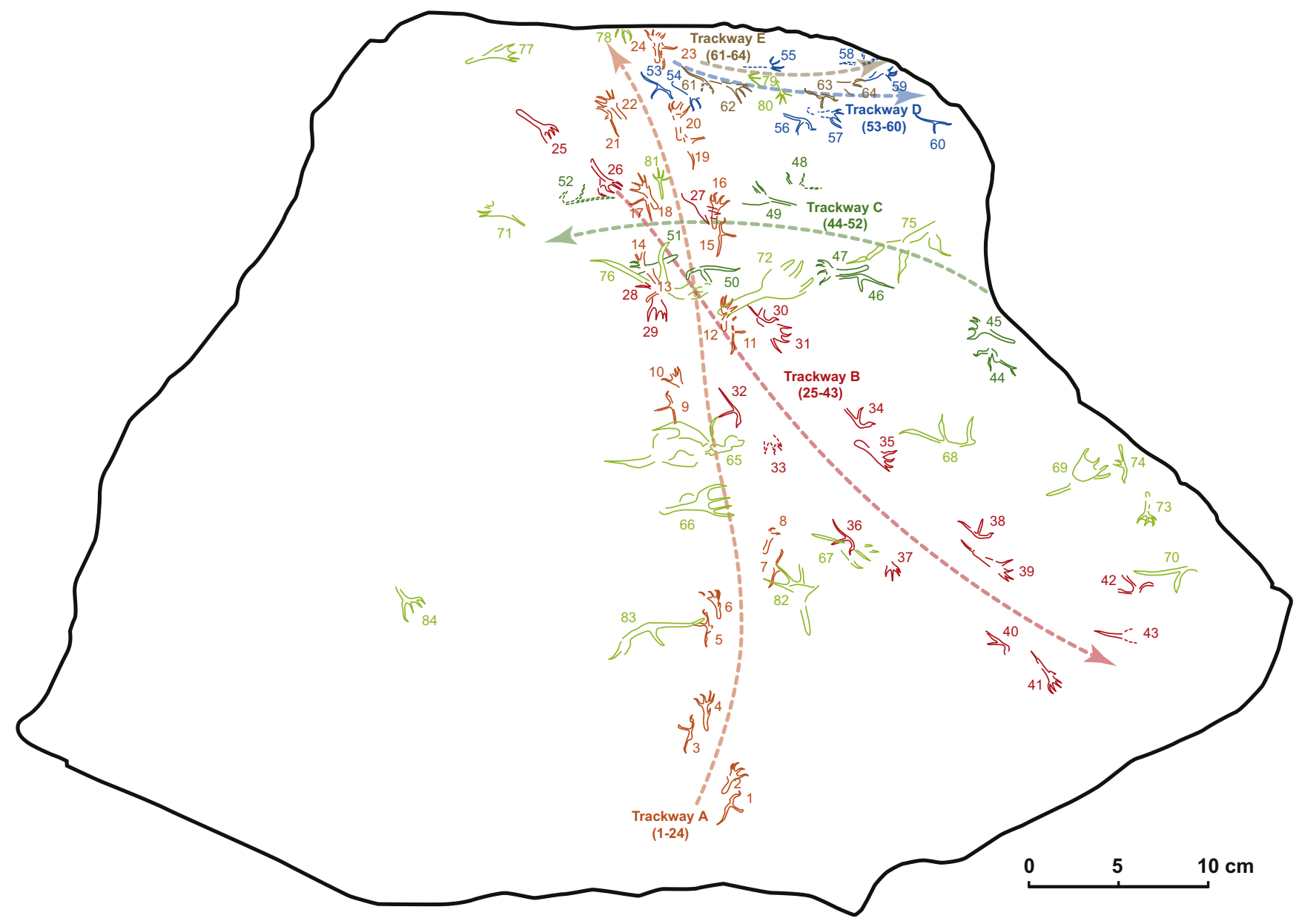

Fig. 5. Drawing of five trackways of Pteraichnus nipponensis isp. nov., with 20 isolated pterosaur tracks. 


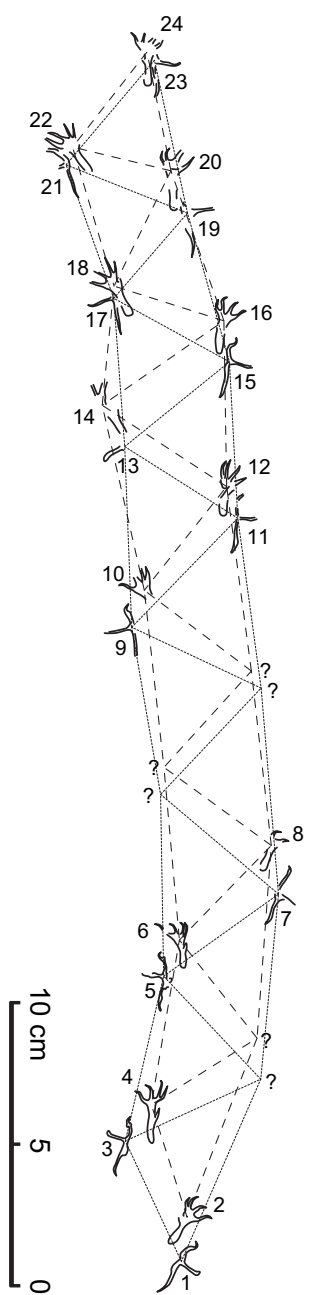

Trackway A

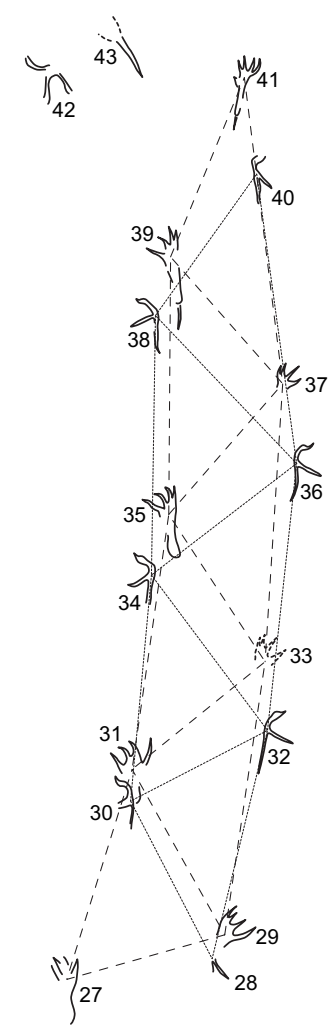

$$
\text { M) }
$$

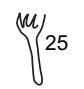

Trackway B

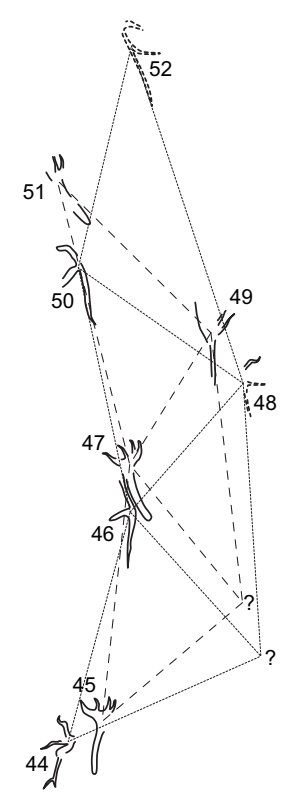

Trackway C

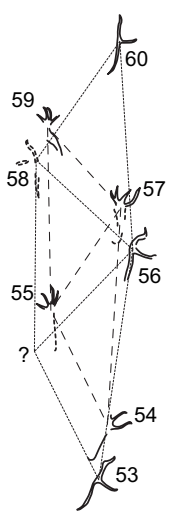

Trackway D

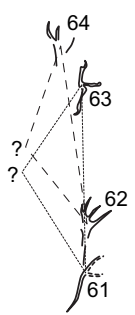

Trackway E

Fig. 6. Five trackways of Pteraichnus nipponensis isp. nov.

The first Asian ichnospecies of Pteraichnus, P. koreanensis, was recently described from the Hasandong Formation in Korea (Lee et al., 2008). It is very similar to P. nipponensis in size but different from each other in morphology. Firstly, the digit I imprint of $P$. koreanensis is anterolaterally oriented and is the shortest among the three digits, which is different from $P$. nipponensis, having anteriorly oriented digit I imprint as almost same as digit II in length. Thus, the divarication between the digit I and III of P. koreanensis (average $116.2^{\circ}$ ) is much smaller than that of $P$. nipponensis $\left(155.4^{\circ}\right)$. Also, the claw mark of the digit I imprint is not clear in the former, but is very distinct in the latter that makes a clear hook-like sharp claw mark curved medially. Frey et al. (2003) suggested that at least two different types of manus among the pterosaurs by the abduction of claw while walking. Namely, $P$. nipponensis could be made by a short-clawed type of pterosaur while $P$. koreanensis made by an azhdarchid-type or Pterodactylustype pterosaur with huge claws, provided the claws were abducted during terrestrial locomotion. It is difficult to compare the pes morphology of $P$. nipponensis directly with that of $P$. koreanensis because the latter is not clearly preserved. The differences between two ichnospecies above might be consider as small degree of variability made by the interaction between trackmaker dynamics and the substrate, however all diagnostic features shown consistently in the five trackways of $P$. nipponensis clearly indicate that it is not a such case at all.
Although the taxonomic studies have not performed yet, more than 30 pterosaur trackways were excavated in Crayssac (Lower Tithonian), southwestern France (Mazin et al., 1995, 1997). They could be assigned to different pterosaurian track-makers and correspond to several ichnospecies (Mazin et al., 2003). Among several different print morphotypes, CR99.43 trackway (Pteraichnus isp.) is very similar to Pteraichnus nipponensis in size and general morphology (Mazin et al., 2003, fig. 1e). Very wide divarication between manus' digit I and III (more or less $180^{\circ}$ ) and distally hooked claw mark in digit I are common in Pteraichnus nipponensis and CR99.43 (Mazin et al., 2003, fig. 3c). However, the convex webbing mark to reach the tips of pes claws (Mazin et al., 2003, fig. 2d) is clearly distinguished from that of Pteraichnus nipponensis.

Through comparsions $P$. nipponensis to previously known ichnospecies of Pteraichnus and Crayssac pterosaur tracks, we conclude that it can be distinguished from others in morphology. Therefore, we assign the Kitadani five pterosaur trackways to the new ichnospecies of Pteraichnus because it meets the updated diagnosis of the genus and has several distinct autapomorphies.

Except five trackways $(n=64)$, there are 20 isolated pterosaur tracks comprising seven manus and thirteen pes imprints. Although some tracks could be manus-pes sets in these tracks, it is very difficult to clarify the trackway. The isolated manus prints range from $21.9 \mathrm{~mm}$ to $69.2 \mathrm{~mm}$ in length while pes prints range from $13.0 \mathrm{~mm}$ to $56.3 \mathrm{~mm}$ in length. The morphology of isolated 


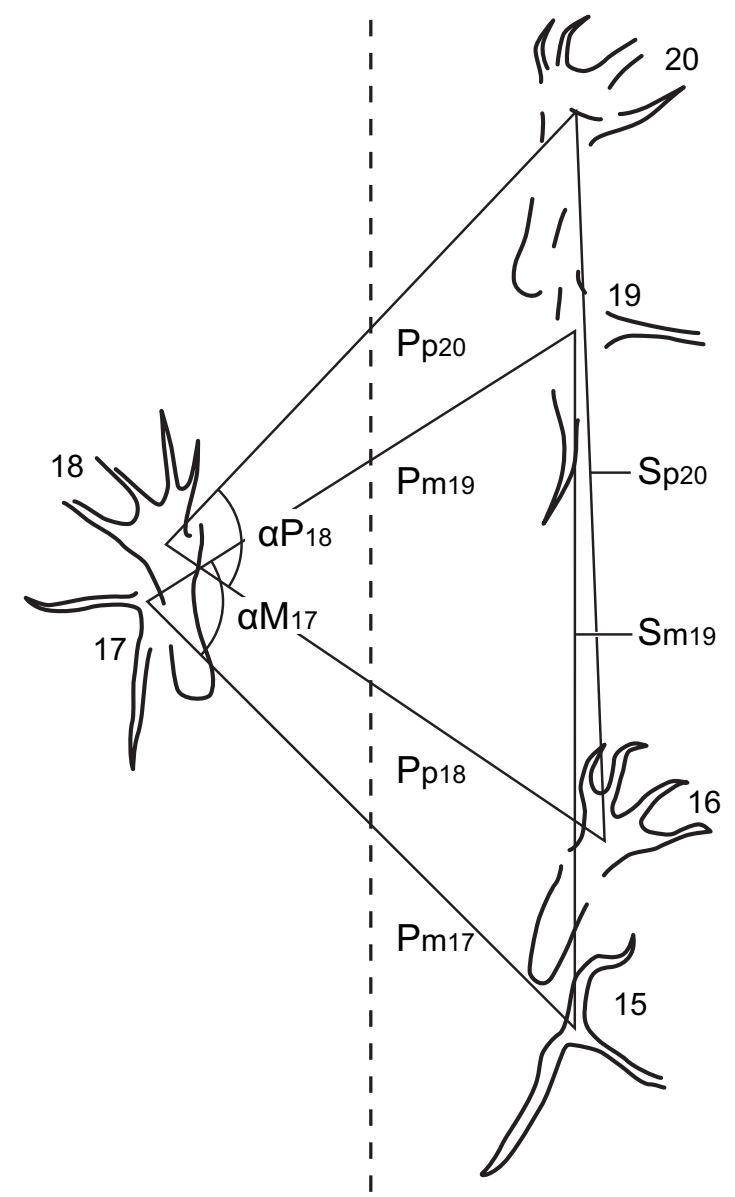

Fig. 7. A complete locomotion cycle of Pteraichnus nipponensis isp. nov. (N15 20). Abbreviations: $\alpha \mathrm{M}$, pace angel of manus; $\alpha \mathrm{P}$, pace angle of pes; Pm, pace of manus; Pp, pace of pes; Sm, stride of manus; Sp, stride of pes.

pes imprints regardless of size is very similar to $P$. nipponensis, but that of manus prints is not, especially in big tracks (N 68, 75, 76, 83). The claw mark of the first digit is strongly bent laterally in these tracks unlike $P$. nipponensis. So, it is not certain that it suggests the ontogenetic behavioral variation of $P$. nipponensis or different ichnotaxon. Therefore, it is reasonable that the holotype of $P$. nipponensis confine to five trackways except for these isolated tracks.

It is reasonable that five trackways of $P$. nipponensis were made by the same kind of animals at similar ages because all manus and pes imprints show a very low amount of variability in size and morphology, as well as in trackway pattern (Fig. 6). The possibility that the tracks represent juveniles and not adults cannot be excluded, but determining this is beyond the scope of this study. The small degree of variability such as the pace and stride length as well as the pace angulation could correspond to the interaction between trackmaker dynamics and the substrate (Mazin et al., 2003), or individual variations. Moreover, considering the small size and consistency of very shallow track depth (less than $2 \mathrm{~mm}$ ) in such a small area, the tracks were probably made in a short period of time.

\section{Discussion}

There is a little variability in print morphology, as well as in trackway pattern for five trackways of Pteraichnus nipponensis. The pes and manus length are almost consistent along the same trackway (Fig. 6, Table 1). The digit spread of the pes is also consistent for the same pes along a single trackway. This indicates that pterosaurs walked on a competent substrate, reflecting their detailed anatomy of the feet. Hence, Kitadani pterosaur trackways show the reliable 'ichnoanatomic' features rather than 'ichnodynamic' ones (sensu Mazin et al., 2003). Firstly, a high divarication of manus digit' I and III (average $155.4^{\circ}$ ) is very characteristic in Pteraichnus nipponensis. The high digital abduction (more than $155^{\circ}$ ) is also observed in some manus prints from Crayssac (reach $180^{\circ}$ or more) as well as P. parvus from Soria. Unwin (1997) noted that the digit III could be abducted up to and beyond $90^{\circ}$ to the digit I, implying that the metacarpo-phalangeal joint was not strongly restrictive and permitted a considerable degree of lateral as well as vertical movement based on the interpretation of the functional anatomy in several pterosaur taxa. It was enforced by the observation of a large abductor tubercle on the proximal phalanx of digit III of Pteranodon and Pterodactylus (Bennett, 1997). The trackways above having the high digital abduction including Pteraichnus nipponensis clearly shows that the digit I of manus could be more hyper-extended anteriorly than previously thought. Mazin et al. (2003) mentioned that this feature cannot be excluded that the movement of the manus digits through the surface may exaggerate the apparent angle of divarication when the substrate is incompetent. However, it is clearly not in the case of Pteraichnus nipponensis. The spreading the digits as much as possible would provide a more stable contact with the substrate as well as better support the center of body mass displaced anteriorly.

Secondly, the trackway B is different from other trackways in the occurrence of 'pes-only' imprints. The pes-only prints are unusual while the manus-only trackways are common because the center of body mass in pterodactyloid pterosaurs is anteriorly displaced (Bramwell and Whitfield, 1974; Bennett, 1997; Mazin et al., 2003). If they represent a real pterosaur behavior, the first three pes-only prints (N 25-27) with an incompletely impressed manus print (N 28) in the first manus-pes set $(\mathrm{N} \mathrm{28,29)}$ would indicate the landing marks which made first only by pes and then the animal moved forward with normal quadrupedal gait pattern. The first landing marks of the pterosaur were reported from Crayssac (Billon-Bruyat et al., 2006). They interpreted based on the trackway that a small pterodactyloid (pes length $\sim 5 \mathrm{~cm}$ ) did not make a running landing. Trackway B shows that a small pterodactyloid (pes length $\sim 2.3 \mathrm{~cm}$ ) did not make a running landing either, but landed first by a left pes (N 25) and proceeded almost immediately by a next right step ( $\mathrm{N} 26)$ rather than landed on both feet in parallel. And then, the first right manus (N 28) touched slightly (only digit I and II impression) and followed the second left pes ( $\mathrm{N}$ 27). At this point, the animal began to walk normally such as LP (N27)-LM (N30)-RP (N29)-RM (N32) (Fig. 6, Trackway B).

From all five trackways, both manus and pes imprints show the positive rotation (outward rotation), but the rotation of pes imprints is larger than that of manus. The manus gait-width is slightly longer than pes gait-width. Thus, the pace angulation of pes is a little bigger than that of manus (Table 1, Fig. 7). The low gaitwidth ratio (manus gait-width/pes gait-width) of five trackways indicates that these pterosaurs walked at low-velocity in a semierect stance (Mazin et al., 2003).

The taxonomic identification of a trackmaker depends on the diagnostic features preserved in the trackway integrated with skeletal data (Olsen, 1995; Carrano and Wilson, 2001). In addition to pterosaur tracks, an incomplete pterosaur bone has been found in Japan. It is an incomplete azhdarchid cervical vertebra from the Mifune Group (late Cenomanian early Turonian), Kumamoto Prefecture, Japan (Ikegami et al., 2000). The estimated size of the pterosaur based on that bone and its stratigraphic occurrence different from the late Barremian Kitadani Formation indicate that the Kumamoto pterosaur cannot be a track-maker of $P$. nipponensis. 
Even though we may try to infer the track-maker of $P$. nipponensis from the abundant Jehol pterosaur assemblage (Wang et al., 2005; Lü and Ji, 2006) because the age of the Kitadani Formation is nearly equivalent to that of the Jehol Group (Swisher et al., 1999; He et al., 2004), it is not necessary before bone materials are found in the track site or in that formation.

Since the first pterosaur trackway (Pteraichnus saltwashensis) came from the Morrison Formation (Upper Jurassic), four new ichnospecies of Pteraichnus have been reported from the Lower Cretaceous sediments of Spain, Korea, and Japan so far. Manus imprints of four ichnospecies are less than $30 \mathrm{~mm}$ in length. The Jehol pterosaurs in China include a wide range of taxa, including both basal and derived, and ranging from anurognathids to tapejarids (Lü et al., 2006). Among the small taxa comparable with small ichnospecies are Dendrorhynchoides curvidentatus (Ji and Ji, 1998; Ji et al., 1999) and Nemicolopterus crypticus (Wang et al., 2008) in which the manus and pes lengths are less than $30 \mathrm{~mm}$. However, the former is a basal anurognathid, rather than a derived pterodactyloid and the latter is a juvenile dsungaripteroid. Thus, skeletal data of the Early Cretaceous pterosaurs do not match with the abundant ichnologic data of small pterosaurs. It was alleged that there is a remarkable degree of congruency in size between pterosaur body fossils and tracks (Hwang et al., 2002) such as a distinct new range of larger pterosaurs evolved from the Cretaceous. Although we do not yet have skeletal evidence, it seems that pterosaur evolution was not simple. Abundant small pterosaur ichnotaxa indicate that many small pterodactyloid pterosaur species existed in the Early Cretaceous. This small track diversity implies that there is a strong bias for the collection and occurrence of pterosaur specimens. Small specimens had relatively less chance to be preserved as fossils than larger specimens, especially in flying animals with very thin bone (Ricqlès et al., 2000). Thus, a new discovery of pterosaur trackways, $P$. nipponensis, adds an important datum to the pterosaur ichnologic database, which complements the biases and gaps in the skeletal record, offering new insights into the more reliable fossil record and paleoecology of pterosaurs.

\section{Acknowledgements}

For the excavation in 1990, we are deeply indebted to the field crews of Fukui Prefectural Museum, the predecessor of the present Fukui Prefectural Dinosaur Museum. Thanks also go to Drs. Masato Fujita and Yoshikazu Noda for providing valuable field data. This research was supported by the Basic Research Project (No. 09-3111) of the Korea Institute of Geoscience and Mineral Resources (KIGAM) funded by the Ministry of Knowledge Economy of Korea to the first author and by the Fukui Prefectural Government to the second author. The authors sincerely thank two anonymous reviewers for their helpful discussions and suggestions to improve the manuscript.

\section{References}

Azuma, Y., 2003. Early Cretaceous vertebrate remains from Katsuyama City, Fukui Prefecture, Japan. Memoir of the Fukui Prefectural Dinosaur Museum 2, 17-21. Azuma, Y., Currie, P.J., 2000. A new carnosaur (Dinosauria: Theropoda) from the Lower Cretaceous of Japan. Canadian Journal of Earth Sciences 37, 1735-12753.

Bennett, S.C., 1997. Terrestrial locomotion of pterosaurs: a reconstruction based on Pteraichnus tracks. Journal of Vertebrate Paleontology 17, 104-113.

Billon-Bruyat, J.-P., Mazin, J.-M., 2003. The systematic problem of tetrapod ichnotaxa: the case study of Pteraichnus Stokes, 1957 (Pterosauria, Pterodactyloidea). In: Buffetaut, E., Mazin, J.-M. (Eds.), Evolution and Palaeobiology of Pterosaurs, 217. Geological Society, London, pp. 315-324. Special Publication.

Billon-Bruyat, J.-P., Mazin, J.-M., Padian, K., 2006. First record of a pterosaur landing trackway. In: Proceedings of the 4th Swiss Geoscience Meeting, Bern, pp. 22.

Board of Education of Toyama Prefecture, 2002. Report of the Geological Survey of the Tetori Group in Toyama Prefecture. Board of Education of Toyama Prefecture, Toyama, $60 \mathrm{pp}$
Bramwell, C.D., Whitfield, G.R., 1974. Biomechanics of Pteranodon. Philosophical Transactions of the Royal Society of London (B) 267, 503-581.

Calvo, J.O., Lockley, M.G., 2001. The first pterosaur tracks from Gondwana. Cretaceous Research 22, 585-590.

Carrano, M.T., Wilson, J.A., 2001. Taxon distributions and the tetrapod track record. Paleobiology 27, 564-582.

Currie, P.J., Azuma, Y., 2006. New specimens, including a growth series, of Fukuiraptor (Dinosauria, Theropoda) from the Lower Cretaceous Kitadani quarry of Japan. Journal of Paleontological Society of Korea 22, 173-193.

Frey, E., Tischlinger, H., Buchy, M.-C., Martill, D.M., 2003. New specimens of Pterosauria (Reptilia) with soft parts with implications for pterosaurian anatomy and locomotion. In: Buffetaut, E., Mazin, J.-M. (Eds.), Evolution and Palaeobiology of Pterosaurs, 217. Geological Society, London, pp. 233-266. Special Publication.

Fuentes Vidarte, C., 2001. A new species of Pteraichnus for the Spanish Lower Cretaceous: Pteraichnus cidaco. Strata 11, 44-46.

Fuentes Vidarte, C., Meijide Calvo, M., Meijide Fuentes, F., Meijide Fuentes, M. 2004a. Pteraichnus longipodus nov. ichnosp. en la Sierra de Oncala (Soria España). Stuida Geologica Salmanticensia 40, 103-114.

Fuentes Vidarte, C., Meijide Calvo, M., Meijide Fuentes, M., Meijide Fuentes, F. 2004b. Huellas de Pterosaurios en la Sierra de Oncala (Soria, España), Nuevas Ichnospecies: Pteraichnus vetustior, Pteraichnus parvus, Pteraichnus manueli. Celtiberia 98, 471-490.

Fujita, M., 2003. Geological age and correlation of the vertebrate-bearing horizons in the Tetori Group. Memoir of the Fukui Prefectural Dinosaur Museum 2, 3-14.

Fujita, M., 2008. Dinosaur tracks from the Tetori Group. In: Abstracts of the International Dinosaur Symposium in Fukui 2008. pp. 33-36.

Garcia-Ramos, J.C., Pinuela, L., Lires, J., Fernadez, L.A., 2000. Icnitas de reptiles voladores (pterosaurios) con impressions de la peil en el Jurassic Superior de Asturias (N. de España). In: Diez, J.B., Balbino, A.C. (Eds.), Primero Congresso Iberico de Paleontologia XVI Journadas de la Socieded Española de Paleontologica Evora (Portugal), pp. 87.

Gifu-ken Dinosaur Research Committee, 1993. Report on the Dinosaur Fossil Excavation in Gifu Prefecture, Japan. Gifu Prefectural Museum, Gifu, 46 pp.

He, H.Y., Wang, X.L., Zhou, Z.H., Wang, F., Boven, A., Shi, G.H., Zhu, R.X., 2004. Timing of the Jiufotang Formation (Jehol Group) in Liaoning, northeastern China, and its implications. Geophysical Research Letters 31, L12605.

Hirayama, R., 2002. Preliminary report of the fossil turtles from the Kitadani Formation (Early Cretaceous) of the Tetori Group of Katsuyama, Fukui Prefecture, Central Japan. Memoir of the Fukui Prefectural Dinosaur Museum 1, 29-40.

Hwang, K.G., Huh, M., Lockley, M.G., Unwin, D.M., Wright, J.L., 2002. New pterosaur tracks (Pteraichnidae) from the Late Cretaceous Uhangri Formation, southwestern Korea. Geological Magazine 139, 421-435.

Ikegami, N., Kellner, A.W.A., Tomida, Y., 2000. The presence of an azhdarchid pterosaur in the Cretaceous of Japan. Paleontological Research 4, 165-170.

Isaji, S., 1993. Nippononaia ryosekiana (Bivalvia, Mollusca) from the Tetori Group in Central Japan. Bulletin of the National Science Museum, Tokyo, Series C 19, 65-71.

Ji, S.A., Ji, Q., 1998. A new fossil pterosaur (Rhamphorhynchoidea) from Liaoning. Jiangsu Geology 22, 199-206.

Ji, S.A., Ji, Q., Padian, K., 1999. Biostratigraphy of new pterosaur from China. Nature 398, 573-574

Kaup, J., 1834. Versuch einer Eintäeilung der Säugetiere. Isis von Oken 315.

Kim, J.Y., Kim, S.H., Kim, K.S., Lockley, M.G., 2006. The oldest record of webbed bird and pterosaur tracks from South Korea (Cretaceous Haman Formation, Changseon and Sinsu Islands): more evidence of high avian diversity in East Asia. Cretaceous Research 27, 56-69.

Kobayashi, Y., 1998. A new goniopholidid from the Early Cretaceous Kitadani Formation, Fukui Prefecture, Japan. Journal of Vertebrate Paleontology 18 (Suppl. 3), 56A.

Kobayashi, Y., Azuma, Y., 2003. A new iguanodontian (Dinosauria: Ornithopoda) from the Lower Cretaceous Kitadani Formation of Fukui Prefecture, Japan. Journal of Vertebrate Paleontology 23, 166-175.

Kozai, T. Ishida, K, Park, S.O., Chang, K.H., 2002. Early Cretaceous nonmarine bivalves from Korea and Japan. In: Abstracts of the 2002 Annual Meeting of the Palaeontological Society of Japan, pp. 16-17.

Kubota, K., 2005. Charophyte gyrogonites from the Lower Cretaceous Kitadani Formation of the Tetori Group in the Takinamigawa area, Katsuyama City, Fukui Prefecture, central Japan. Paleontological Research 9, 203-213.

Lee, Y.-N., Lee, H.-J., Lü, J., Kobayashi, Y., 2008. New pterosaur tracks from the Hasandong Formation (Lower Cretaceous) of Hadong County, South Korea. Cretaceous Research 29, 345-353.

Lee, Y.S., Nishimura, S., Min, G.D., 1996. Paleomagnetotectonics of East Asia in the Proto-Tethys Ocean. Tectonophysics 270, 157-166.

Li, D., Azuma, Y., Fujita, M., Lee, Y.-N., Arakawa, Y., 2006. A preliminary report on two new vertebrate track sites including dinosaurs from the Early Cretaceous Hekou Group, Gansu Province, China. Journal of Paleontological Society of Korea 22, 29-49.

Lockley, M.G., Logue, T.J., Moratalla, J.J., Hunt, A.P., Schultz, R.J., Robinson, J.W., 1995 The fossil trackway Pteraichnus is pterosaurian, not crocodilian: implications from the global distribution of pterosaur tracks. Ichnos 4, 7-20.

Lockley, M.G., Huh, M., Lim, S.K., Yang, S.Y., Chun, S.S., Unwin, D.M., 1997. First report of pterosaur tracks from Asia, Chullanam Province, Korea. In: Yang, S.Y., Huh, M. Lee, Y.-N., Lockley, M.G. (Eds.), International Dinosaur Symposium for Uhangri 
Dinosaur Center and Theme Park in Korea. Journal of Paleontological Society of Korea No. 2, 17-32. Special Publication.

Lockley, M.G., Wright, J., Langston, W., West, E., 2001. New pterosaur tracks specimens and tracksites in the Late Jurassic of Oklahoma and Colorado: their paleobiological significance and regional ichnological context. Modern Geology 20, 179-203.

Lü, J., Ji, Q., 2006. Preliminary results of a phylogenetic analysis of the pterosaurs from western Liaoning and surrounding areas. Journal of Paleontological Society of Korea 22, 239-261.

Lü, J., Ji, S., Yuan, C., Ji, Q., 2006. Pterosaurs from China. Geological Publishing House, Beijing, China, $147 \mathrm{pp}$.

Maeda, S., 1962. Some Lower Cretaceous pelecypods from the Akaiwa Subgroup, the upper division of the Tetori Group in Central Japan. New Series. Transactions and Proceedings of the Palaeontological Society of Japan 48, 343-351.

Mazin, J.-M., Hantzpergue, P., Lafaurie, G., Vignaud, P., 1995. Des pistes de pterosaurs dans le Tithonien de Crayssac (Quercy, France). Comptes Rendus de l' Académie des Sciences, Paris, Séire IIa 321, 417-424.

Mazin, J.-M., Hantzpergue, P., Bassoullet, J.-P., Lafaurie, G., Vignaud, P., 1997. Le gisement de Crayssac (Tithonien inférieur, Quercy, Lot, France): découverte de pistes de dinosaurs en place et premier bilan ichnologique. Comptes Rendus de l' Académie des Sciences, Paris, Séire IIa 325, 733-739.

Mazin, J.-M., Billon-Bruyat, J.-P., Hantzpergue, P., Lafaurie, G., 2003. Ichnological evidence for quadrupedal locomotion in pterodactyloid pterosaurs: trackways from the Late Jurassic of Crayssac (southwestern France). In: Buffetaut, E. Mazin, J.-M. (Eds.), Evolution and Palaeobiology of Pterosaurs, 217. Geological Society, London, pp. 283-296. Special Publication.

Meijide Calvo, M., 2001. Pterosaur tracks in Oncala berriasian (Soria, Spain), new ichnospecies: Pteraichnus manueli. Strata 11, 72-74.

Meijide Fuentes, F., 2001. Pterosaur tracks in Oncala mountain range (Soria, Spain), a new species: Pteraichnus vetustior. Strata 11, 70-71.

Mickelson, D.L., Lockley, M.G., Bishop, J., Kirkland, J., 2004. A new pterosaur tracksite from the Jurassic Summerville Formation, near Ferron, Utah. Ichnos 11, 125-142.

Olsen, P.E., 1995. A new approach for recognizing track makers. Geological Society of America Abstracts with Programs 27, 72.

Otofuji, Y., Matsuda, T., Nohda, S., 1985. Opening mode of the Japan Sea inferred from the palaeomagnetism of the Japan Arc. Nature 317, 603-604.

Pascual Arribas, C., Sanz Pérez, E., 2000. Huellas de pterosaurios en el grupo Oncala (Soria, España). Pteraichnus palaciei-saenzi, nov. ichnosp. Estudios Geológicos $56,73-100$

Plieninger, F., 1901. Beiträge zur Kenntnis der Flugsaurier. Paläontographica 48, $65-90$.
Ricqlés, A.J., Padian, K., Horner, J.R., Francillon-Vieillot, H., 2000. Palaeohistology of the bones of pterosaurs (Reptilia: Archosauria): anatomy, ontogeny, and biomechanical implications. Zoological Journal of the Linnean Society 129, 349-385.

Rodriguez-de la Rosa, R.A., 2003. Pterosaur tracks from the latest Campanian Cerro del Pueblo Formation of southeastern Coahuila, Mexico. In: Buffetaut, E. Mazin, J.-M. (Eds.), Evolution and Palaeobiology of Pterosaurs, 217. Geological Society, London, pp. 275-282. Special Publication.

Sánchez-Hernández, B., Przewieslik, A.G., Benton, M.J., 2009. A reassessment of the Pteraichnus ichnospecies from the Early Cretaceous of Soria Province, Spain. Journal of Vertebrate Paleontology 29, 487-497.

Shibata, M., Azuma, Y., 2008. New dinosaur remains from the Lower Cretaceous Kitadani Formation, Tetori Group of Fukui, Japan. In: Abstracts of the 2008 Annual Meeting of the Palaeontological Society of Japan, Sendai. pp. 21.

Shibata, M., Goto, M., 2008. Report of the 3rd dinosaur excavation project in Katsuyama, Fukui, 2007. Memoir of the Fukui Prefectural Dinosaur Museum 7, 109-116.

Stokes, W.L., 1957. Pterodactyl tracks from the Morrison Formation. Journal of Paleontology 31, 952-954.

Swisher, C.C., Wang, Y.Q., Wang, X.L., Xing, X., Wang, Y., 1999. Cretaceous age for the feathered dinosaurs of Liaoning, China. Nature 400, 58-61.

Tamura, M., 1990. Stratigraphic and palaeontologic studies on nonmarine Cretaceous bivalve faunas in Southwest Japan. Memoirs of the Faculty of Education, Kumamoto University, Natural Science 39, 1-47.

Tashiro, M., Okuhira, K., 1993. Occurrence of Trigonioides from the Lower Cretaceous of Shikoku, and its significance. Geological Reports of Shimane University 12, 1-9.

Unwin, D.M., 1997. Pterosaur tracks and the terrestrial ability of pterosaurs. Lethaia 29, 373-386.

Wang, X.L., Kellner, A.W., Zhou, Z.H., Campos, D., 2005. Pterosaur diversity and faunal turnover in Cretaceous terrestrial ecosystems in China. Nature 473, 875-879.

Wang, X.L., Kellner, A.W.A., Zhou, Z.H., Campos, D., 2008. Discovery of a rare arboreal forest-dwelling flying reptile (Pterosauria, Pterodactyloidea) from China. Proceedings of the National Academy of Sciences 105, 1983-1987.

Wright, J.L., Unwin, D.M., Lockley, M.G., Rainforth, E.C., 1997. Pterosaur tracks from the Purbeck limestone Formation of Dorset, England. Proceedings of the Geologists' Association 108, 39-48.

Zhang, J., Li, D., Li, M., Lockley, M.G., Bai, Z., 2006. Diverse dinosaur-, pterosaur-, and bird-track assemblages from the Hekou Formation, Lower Cretaceous of Gansu Province, northwest China. Cretaceous Research 27, 44-55. 